\title{
The Contribution of Under-Preparedness to Low First Year Success Rates as Perceived by Lecturers and second Year Students and at a Comprehensive South African University
}

\author{
George Mavunga
}

Academic Development Centre, University of Johannesburg, Soweto Campus Email: gmavunga@uj.ac.za

Doi:10.5901/mjss.2014.v5n20p1748

\begin{abstract}
Using a qualitative research design, the study sought to establish how second-year students and lecturers' teaching first-year modules perceive the contribution of under-preparedness to low success rates at first-year level. Data were gathered by means of focus group interviews with second year students studying Education, Financial Accounting, Public Management and Governance, Entrepreneurial Studies and Management as well as with five lecturers teaching at first-year level at a campus of the university which is located in a township area. It was established that while both the students and lecturers, in the main, agree that under-preparedness contributes significantly to low first-year success rates, they also agree that it can also be attributed to psycho- social and institutional factors some of which have very little or no link at all to the first-years' basic education background. The study recommends the need for measures to be taken to solve the problems in South African basic education as well enhancement of institutional efforts aimed at improving first-year success rates by universities.
\end{abstract}

Keywords: Under-preparedness, first-year, success, university, basic, education, problems

\section{Introduction}

There has been a massive increase in student enrolments in South African universities since 1994. This has been attributed to attempts by the South African government to correct one of the social ills of the apartheid era - lack of access to higher education by the majority of the black population. The increase in student enrolments has, however, been confronted with a number of challenges. One of these has been the high failure rates amongst university students, especially at first year level. For example, about half of the students who enroll for under-graduate programmes fail to complete their programmes despite entering university as the cream of the matric crop (McFarlane 2012; Mtshali 2013 ).

Low success rates at first year level in South African universities have been attributed to a number of factors. One of these factors is the students' under-preparedness as a result of teething problems in the basic education system. These include failure by government to supply adequate text books, poor learning infrastructure and equipment as well as teacher shortage. A number of studies have been carried out on under-preparedness among university students in South Africa (Bradbury and Miller 2011; Van Schalkwyk 2008 and Maher 2011). Most of these studies, however, have focused on quantifying the under-preparedness. They have also tended to give foregone conclusions on how it impacts negatively on students' achievement, especially at first-year level. One particular study which discusses how students and their lecturers themselves perceive the extent of the contribution of under-preparedness to low success rates is that by van Schalkwyk (2008). This study, however, focuses only on students and lecturers' perceptions of the contribution of poor academic literacy to low success rates at first-year level. There is therefore a dearth of studies on lecturers and students' holistic view of the extent to which under-preparedness contributes to low first-year success rates. Yet Troike in Riveria (1984:50) argues that academic outcomes are always complex results of interaction between the personal characteristics of the individual and his or her home or cultural background and the physical, social, cultural and human characteristics of the educational setting.

This article discusses how lecturers and students at a previously blacks-only campus of an urban South African university holistically perceive the factors contributing to low first-year success rates. The campus, which was merged with two other institutions in 2005 to form a metropolitan university, today boasts state-of- the- art teaching and learning facilities.

The next section is a review of the literature on the problems on South African basic education, how they contribute to under-preparedness and, in the final analysis, to low first-year success rates at university level. 


\section{Literature Review}

\subsection{Problems in South African basic education}

The multifaceted problems in South African basic education are said to be largely a legacy of the country's history. The African National Congress (ANC) government is said to have inherited, '... a state education system from the apartheid era that was not only divisive and discriminatory, but also ineffective and inefficient...' (Hartshorne, 1999: 105)

Many learners in the country still face the problem of access to schools. In some parts of the country learners still walk more than ten kilometers to and from school (Veriava 2013). Another problem is the shortage of teachers. For example, a 2008 Sunday Times report indicated that the Department of Education had vacancies for 94000 teachers (Govender in Booyse, le Roux, Seroto \& Wolhuter 2012). Currently, the deficit in Maths and Science teachers stands at 2800 and 2500 respectively (Msthali 2013). A considerably high percentage of classes in the system therefore goes untaught every day as also recently demonstrated by media reports of learners at a school in Ekhuruleni, near Johannesburg planning to march to the offices of the Department of Basic Education to picket over the fact that they had not had Mathematics lessons for over two months due to the absence of their teacher. The teacher was on sick leave and the school had failed to find a replacement. This perhaps explains why the Minister of Basic Education is considering the setting up of a directorate for Maths, Science and Technology to improve the quality of teaching in these areas (Govender 2013). Aggravating this problem is high teacher absenteeism which stands at between 10 and $12 \%$ per day (Spaull, 2013).

Questions are also raised about teacher competence in South Africa. The recent admission by the head of the Teacher Development Unit in the Department of Basic Education, that teacher's poor subject knowledge is a fundamental problem in the school system is demonstrative of this problem (Child 2013). Furthermore, a 2012 survey by the unit involving 133 urban schools showed that because of poor teaching, early grade learners' ability to read is so weak that they are likely to struggle for the rest of their school years. Where Maths is concerned, teaching in South African schools is said to be amongst the worst in the world (Bernstein, McCarthy and Oliphant 2013). This is corroborated by a study which revealed that $46 \%$ of teachers were unable to work out the answer to $10 \times 2+(6-4) / 2$ (Child 2013). A 2007 study also revealed that the majority of Grade 6 teachers in the country could not answer questions based on the Grade 6 curriculum (Bernstein, McCarthy and Oliphant 2013). Similarly illustrative of the weak quality of teachers is a recent report of a District Grade Seven English Language examination in Mpumalanga Province which was littered with so many grammatical, punctuation, sentence construction and spelling errors that the teacher who had set it had to be removed from that responsibility and given a warning (Mtshali, 2013).

Teaching in South Africa is also said to be too unionized for the good of the education system. The unions wield so much political power that that they flex their muscles in their favor when it suits them. Sadly, though, when teachers go on strike at the behest of the unions, it is pupils from the rural areas and poor townships who suffer the most. To make matters worse, the unions, it is alleged, often protect some of their members who engage in anti-social and antieducational activities (Bloch 2009).

Joshua and Adelabu (2012) conclude that poor infrastructure and equipment impair learning and are a threat to good effective achievement even in their post-school academic endeavors. This problem is still prevalent in South Africa. For example, there are reports of schools in provinces such as the Eastern Cape and Limpopo where classes are still being conducted either under trees or in pole and mud structures. Overcrowding is so bad at some schools that the only pedagogical approach feasible is preaching (Davids 2013). At some schools the shortage of classrooms forces teachers to teach several grades in one classroom (Davids 2013). In addition, a large number of schools in the country lack basic facilities such as libraries and toilets (Bloch 2009; Veriava 2013). It will therefore come as no big surprise if learners coming out of such a system are lacking in some basic academic skills. A poignant pointer to this problem is the case of Moshesh Senior Secondary School in the Eastern Cape where the pupils took the Minister of Basic Education to court in a bid to force her to improve both the infrastructure and administration at their school (Skiti 2013).

With respect to ICT, in 2010 less than $30 \%$ of schools in the country and only $6 \%$ of the classrooms had access to the internet (Spaull 2012). These infrastructural and technological problems are said to be further compounded by the constant changes in the curriculum. Teachers therefore often find themselves at the deep end without adequate support and training on how to handle new curriculum changes (Nkosi 2012).

Furthermore, the South African education system is said to be deceptive in terms of the matric pass benchmark which, at $30 \%$ is blamed for degrading education standards. Politicians are thus blamed for hoodwinking the country into celebrating mediocrity with respect to the so-called continued improvement in the matric pass rate. So unhappy are some academics and politicians with this pass mark that they say the country's education system today is worse than the Bantu 
education of the 1970's (Mtshali 2012). For example, Jansen observes that a learner can be completely ignorant of more than half the subject matter content and still pass (Nyakudya 2013).

Numeracy is defined by http://www.careers.manchester.ac.uk as '...the ability to handle numbers including, the basic skills of addition, subtraction, multiplication, division and percentages.' According to http://wwwmyigdis there is a growing body of evidence from research which shows that development of early numeracy and mathematics skills are indeed predictors of academic success in later life. Numeracy and mathematics teaching and learning in the South African primary and high school system are in quite a dire situation. For example, no district in Gauteng and the Western Cape had more than 50\% of learners sitting for Mathematics in 2012 (Prew, 2013). In addition, 84 high schools in the country did not offer Mathematics for Grades 10, 11 and 12 in 2012 (Chipangura, 2013). The reduced number of pupils doing Mathematics is a result of the pupils opting for Maths Literacy which they have a higher chance of passing than Pure Maths. The problem, however, is that most universities do not enroll students with a poor mathematical background into mathematics-based programmes. This is confirmed by Bowie's conclusion that learners who do not have adequate preparation in basic mathematics not only struggle to make sense of algebra but also have reduced chances of entering technical or scientific fields post high school (Chipangura, 2013). Most of those who are fortunate enough to be enrolled into such programmes without the requisite passes usually struggle and often drop out or fail to graduate within the minimum time.

Closely related to the problem of numeracy is that of literacy. Recent research by the Evaluation Unit in the Department of Basic Education showed that $13 \%$ of Grade Five pupils were illiterate and that only $5 \%$ of them could read at the required rate of eighty to ninety words per minute (Jansen, 2013). The unit places this state of affairs on teachers' inability to teach reading and describes the situation as a national catastrophe with long term negative effects on the country's education system.

Another problem facing the South African basic education system is the shortage of the basic teaching and learning tools such as textbooks. This is epitomized by the Limpopo text book saga as a result of which learners in some grades at schools in Limpopo Province went without textbooks for the greater part of 2012. Even in 2013 the government is said to have allocated only about half of the half of the money needed to ensure that all pupils have all the necessary textbooks (Nkosi, 2013).

The problems afflicting South African basic education go beyond the school. A large percentage of the South African population still lives in poverty. Most families can therefore not provide the conditions necessary for children to pursue academic interests (Bloch, 2009). This is worsened by the lack of school support services such as psychological services which are needed mostly by learners from poor backgrounds. Yet it is such learners who are most in need of help. They are the ones who are most likely to be robbed, raped, traumatized or disadvantaged (Verrijdt, 2012).

\subsection{The impact of a poor basic education on success rates at university}

There is general consensus that the problems of poor basic education and its attendant ramifications carry over to higher education. Mtshali (2008: 8) quotes Moeketsi as saying , 'You can't have a good higher education sector if you have a shaky basic education system...' In other words, the poor quality of basic education in the country has a knock-on effect at universities (Crous, 2013). For example, the National Benchmark Tests (NBT's) over the years have shown serious under-achievement by South African university students in terms of numeracy and literacy. A case in point is the 2009 NBT's which showed that only $47 \%$ of the students were proficient in English; $46 \%$ were at intermediate level while $7 \%$ had only basic academic literacy. This points to serious under-preparedness on the part of most first-year students as difficulties with the medium of instruction and basic numeracy undoubtedly lead to poor performance and low throughput rates. As a result of the width of the school-university gap, the Council for Higher Education recently proposed a university curriculum which is sensitive to the different levels of students' preparedness and gives them more time to complete their programmes. According to Mtshali (2013:18) this would lead to

...four years for diplomas and general bachelor's degrees and five years for level-eight professional bachelor's degrees.

The challenges facing first-year students are said to be even greater with respect to quantitative literacy and mathematics. For example, the 2009 NBT's showed that only a quarter of students were proficient in quantitative literacy, while half attained intermediate and 25\% 'basic' levels (http://www.universityworldnews.com). The test results also revealed that only $7 \%$ of students were proficient in the tests, which measured the skills needed to study first-year mathematics; $73 \%$ had intermediate skills and would need assistance to pass, while $20 \%$ had basic skills and would need long term support. This points to a very high possibility of the majority of students studying mathematics-related subjects failing these subjects. Yet, as http://www.universityworldnews.com says, 
very few universities make any structured provision for developing student knowledge and skills in this domain, despite its central place in most disciplines, where students are required to interpret tables, understand percentages, basic proportions and trends.

The amount of resources committed to intervention programmes aimed at tackling the problem of underpreparedness on the part of first-year students further demonstrates the extent of the problem. For example, according to MacFarlane (2012:13) in his 2012 budget speech, Blade Nzimande, the Minister of Higher Education and Training committed R 700 million, "...to help students who were woefully underprepared for academic study by low-quality schooling." This was in a bid to solve the problem of poor performance by first-year students at the country's twenty three state-supported universities "... where about $40 \%$ of registered students drop out of their studies during or at the end of their first year and only about 15\% obtain their degrees in the minimum time" (Prince \& Yeld, 2012).

Because of poor linguistic skills, most students from disadvantaged backgrounds face difficulties in understanding the terminology and concepts in university textbooks. Such students are also said to struggle with making impersonal, objective and analytical arguments and also lack basic grammar (Mthethwa, 2013). In the sciences and engineering subjects the problem is that, "For many students in government schools, a science lab is a resource that they never will set foot in!." (Nyakudya 2013, 14). Access to computers and the internet thus becomes an unthinkable prospect for such children. The new physical and social learning environment at university and its attendant discourses therefore become too overwhelming for such students. A large number of them thus perform badly and consequently suffer academic exclusion. However, even students from privileged backgrounds also face challenges in their first year of university (Mthethwa, 2013). This is shown by the fact that, like their counterparts from underprivileged backgrounds, some of them also find themselves facing academic exclusion at the end of the first year. Mthethwa attributes this to failure by even the elite South African high schools to prepare learners for university level in terms of workload, study methods and critical thinking. This is in keeping with the argument that until South Africa begins to focus on how to learn and why that is important, it will have a continuing problem with high numbers of dropouts and a population increasingly unable to see beyond the short-term results (Noon, 2013).

\subsection{The contribution of factors other than under-preparedness to low first-year success rates}

There is acknowledgement locally and internationally of the contribution of factors other than under-preparedness to low first-year success rates. (Riveria, 1984; Tinto 2004; Maher, 2011; Brieir \& le Roux, 2012; Gilmour, Christie \& Soudien, 2012). Tinto, for example, attributes low student success to institutions' fragmented approaches to the problem. He blames institutions for investing in a laundry list of disconnected and uncoordinated actions which, however, fail to impact positively on student retention (Grayson, 2013).

Tinto's model (Figure 1, below) implies the need for a holistic approach to efforts to improve students' success rates. According to the model, when a student enrols at university, he or she has a commitment to a goal which is formulated alongside the institution's own commitment for the student to achieve that goal. Initially, however, the student has feelings of isolation from all stakeholders and entities which will make the realization of the initial goal difficult. The student then goes through a process of both academic and social integration which enable him or her with the transition from the initial feelings of isolation. Academic and social integration within the university help the student to develop even stronger commitment to his or her initial goal commitment which is enhanced by further institutional commitment. This enables the student to become fully integrated within the university's social and academic community. The student therefore becomes more inclined to persistence. This is an imperative for the student's ability to complete his or her programme of study. 


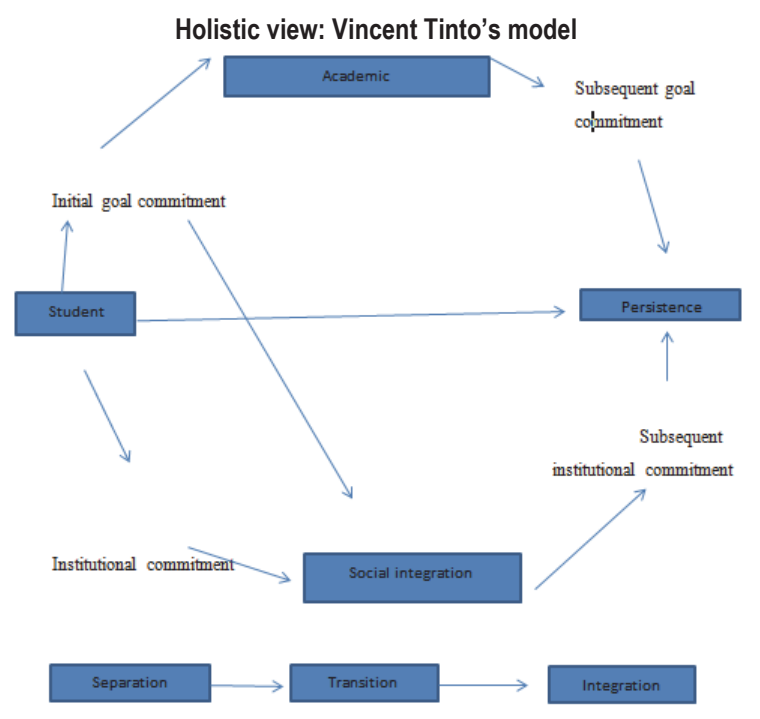

Figure 1. Tinto's model, adapted from Longden $(2004,126)$

Tinto (2002) identifies five conditions which are supportive of persistence. These are expectation, advice, support, involvement and learning. Expectation refers to the need for an institution to put in place certain demands on its students to learn when they enter the institution. An institution which makes clear its learning expectations to its students in terms of learning is therefore more likely to engender a greater sense of perseverance than one which does not. Similarly, an institution which gives its students advice on what and how to learn is more likely to retain more students than one which does not. The third condition, support, refers to all the structures and systems which an institution needs to put in place to ensure successful learning by its students. Involvement refers to the extent to which the students engage in all learningrelevant activities when they enter university. Tinto (2004) argues that the more involved the students are in such activities, the less their chances of dropping out for academic reasons. Learning, according to Tinto (2004) is critical to students realising perseverance because students can only graduate if they learn meaningfully, especially with others. The institutional environment should therefore be such that it fosters learning in its students.

The methods by which data were gathered and analysed will be the focus of the next section.

\section{Methodology}

A qualitative research design employing focus group interviews with second year students and semi-structured interviews with individual lecturers teaching first-years at a campus of the comprehensive University which is located in a township area was used in this study. The students selected for the study were second year students studying education, accounting, entrepreneurial studies, human resource management as well as public management and governance. These students were selected because they had had the experience of going through a complete first year in 2012. Their responses to the questions would therefore be based on their real life experiences and could therefore be relied on to provide useful insights into their perceptions of the contribution of under-preparedness on low first-year success rates at the University. The programmes from which the students were chosen were the ones which are offered at the selected campus of the university.

According to Paton (1987: 23), "A focus group interview is an interview with a small group of people on a specific topic. Groups are typically six to eight people who participate in the interview for half an hour to two hours. The participants are typically a relatively homogenous group of people who are asked to reflect on questions asked by the interviewer." The purpose of the group is to produce qualitative data to "provide insights into the attitudes, perceptions, and opinions of participants" (Krueger, 1994:19). The hallmark of a focus group is the explicit use of the group interaction to produce data and insights that would be less accessible without the interaction found in a group" (Morgan 1988: 12). In this study, the groups consisted of eight students on average. The students were selected on the basis of their programmes of study. Two groups each were selected from students studying Education, Public Management and 
Governance, Entrepreneurial Studies, Financial Accounting and Management at the Soweto Campus. In total eight focus group interviews were conducted. In addition to their programmes of study, the students were also selected on the basis of their availability and willingness to take part in the study. The campus where this study was carried out was selected for the study because it is the campus at which the researcher is based. This convenient in terms of time needed to interact with the research participants. On average each interview lasted thirty five minutes.

The interview questions which the students were asked focused on their perceptions of the contribution of underpreparedness to low first-year success rates as a result of problems faced in basic education in the following areas:

1. numeracy and literacy

2. critical thinking

3. the volume of the content learnt at basic education level

4. learning infrastructure and equipment

The students were also asked questions on the perceptions of the contribution of factors other than underpreparedness to low first-year success rates. The researcher recorded the students' responses in a notebook.

Individual interviews were held with five lecturers teaching first-year students. The lecturers chosen were those whom the researcher knew to have taught at this level for more than a year. The researcher thus considered that their responses would be useful in providing insights into the contribution of under-preparedness to low first-year success rates. This was because these responses would be based on first-hand experiences. The interview was mainly used because it is a very direct way of getting research participants' views on a particular issue (Robson 1995). The interview also gives the researcher an opportunity to ask probing questions and also observe non-verbal cues. This usually provides the researcher with further insights into the participants' view of the issue being researched on. The lecturers were asked questions similar to those which the students were asked. The individual interviews on average lasted thirty minutes. The results were also recorded in a noted book.

A deductive approach to qualitative content analysis was used to analyse the results of the interviews. According to Mayring (2000), in qualitative research, deductive content analysis works with prior formulated theoretical derived aspects of analysis, bringing them in connection with the text. This implies that the researcher condenses the raw data into categories or themes based on valid inference and interpretation. In this case, the results of interviews with both students and lecturers were categorized into themes on the basis their perceptions of the contribution of various factors to low firstyear success rates.

\section{Findings and Discussion}

In keeping with the qualitative research tradition, the findings from the focus group interviews with students and the individual interviews with lecturers will be presented as a descriptive account along selected thematic categories.

\subsection{Perceptions of the contribution under-preparedness in terms of academic literacy and numeracy to low first-year rates}

The students from all the groups were of the view that, there is a wide gap between high school and the first-year of university in terms of academic literacy. The lecturers attributed low success rates, especially in theory subjects where students are expected to write essays and express themselves in their own words to this gap. According to one of the lecturers most first-years fail their modules because, "They cannot read, speak and write properly in English which is the major language of learning at university." A participant from one of the Financial Accounting focus groups also highlighted the nature of the problem across the curriculum when she said, "Even in quantitative subjects, there is a specialized language in which your answers must be expressed so those of us whom high school did not adequately prepare in this regard tend to struggle with most of our first year modules." Most participants, including the lecturers said high school hardly equipped learners with skills such as referencing, question analysis and argumentation which are necessary for success in theory subjects done at first-year level. With respect to numeracy, there is a similar problem. This is because the majority of the students will have done Maths Literacy, instead of Pure Maths. They therefore struggle with subjects such as Statistics and Maths in programmes like Financial Accounting and Education. These findings confirm, the view that if numeracy and literacy are not properly developed early enough in the school system, they can impact negatively on future learning (http://www.careers, manchester.ac.uk). 
4.2 Perceptions of the contribution of under-preparedness in terms of volume of subject content to low first-year success rates.

Two views emerged from the focus group interviews in terms of the extent to which low first-year success rates can be attributed to students' inability to cope with high volumes of content to be learnt. One view was that there was a very wide gap between the volume of content to be learnt at high school and that at university. As one interview participant in one group pointed out, "Most students who are academically excluded at the end of the first year, it is because they can't cope with the volume of work." The second view was that the gap between high school and university in terms of volume of content to be learnt was not very wide. Students who held this view said at some schools learners are forced to take as many as nine subjects at matric level. Such students will find it easy to cope with the volume of work at first year level where the number of modules generally does not exceed five.

There was unanimous agreement amongst the lecturers that the basic education system did not prepare the students adequately for university in terms of the volume of subject content. One of the lecturers remarked, "When you give out learner guides for the first semester, you can read panic on the faces of some of the students when they realize how much they must learn in so short a period. You can clearly tell a significant number of them are not ready for so much work. They are just not used to it." One lecturer also pointed out that the inadequacy in terms of students' readiness for university was also in terms of the nature and quality of the content and the degree to which it engenders critical thinking which is crucial for success at university level. In other words, even if the students brought a lot of knowledge from high school, because of poor articulation, some of it cannot not be used as a scaffold to what they have to learn at university. The inability by students to cope with first year work could partially traced to the $30 \%$ pass mark which academics such as Jansen and have been complaining about (Nyakudya, 2013).

\subsection{Perceptions of the contribution of under-preparedness in terms of infrastructural and learning equipment shortages to low first-year success rates.}

From the focus group interviews, it emerged that indeed some schools in South Africa are so lacking in infrastructure as to incapacitate learners' future learning endeavors. One lecturer pointed out that some Financial Accounting students struggle because, "They will never have used a calculator in their lives and then all of a sudden they are expected to use, not an ordinary one, but a financial calculator." Such students, it also emerged face serious difficulties with computer packages such as Excel and Access which they are expected to be familiar with in the first year. A lecturer teaching an ICT subject in the Faculty of Management also confirmed this when he spoke of the immense challenges faced by students who get to use a computer for the first time only when they come to university. The students also concurred with one of them saying, "Some first year students arrive on campus well after orientation week during which introductory coaching in the use of computers is given. If such students have not been exposed to computers before, they will have a mountain to climb when the actual lectures begin." These observations corroborate the view that poor infrastructure and equipment impair learning even in post-school academic pursuits (Joshua and Adelabu, 2012).

\subsection{Perceptions of the contribution of under-preparedness in terms of teacher-quality to low first-year success rates}

Teacher quality is said to be the single most critical determinant of educational success. In other words, there is generally a positive correlation between good teaching and good educational results (Spaull 2013). In the view of most of the participants in all the focus groups, the effects of poor teaching in South African schools manifest themselves clearly in the first-year of university, if not right up to the final year. In the words of one of the students, "In subjects like Mathematics and Physical Science some high school teachers struggle with basic concepts. Most learners, despite passing matric therefore come to university without a good grasp of concepts which are the foundation of what is taught in the first year of university. This contributes to poor performance by some of these students in the first year." It was, however, pointed by all the lecturers who participated in the interviews that there was good teaching at some schools, especially the well- resourced former Model $\mathrm{C}$ and private schools. "In each class you can identify one or two students who received good teaching," said one of the lecturers.

\subsection{Perceptions of the contribution of factors other than under-preparedness to low first-year success rates}

Results from both the interviews with students and lecturers indicated that low success rates at first year level are also attributable to factors other than under-preparedness. Such factors could be classified into those that are either internal or 
external to the student. The student participants, cited failure to adjust to university life irrespective of one's schooling background as one of the factors internal to the student which leads to failure at first-year level. This could be in terms of failing to cope with living away from home, poor time management and lack of self-discipline in light of the 'new-found freedom' arising from being away from parental control on the part of a large number of students. All the lecturers interviewed concurred, with one of them saying, "For some first-year students, university is a completely new life experience failure to adjust to which can impact negatively on their academic success. This may have nothing to do with whether or not they are academically prepared for their studies."

Forms of risky student behavior such as substance and alcohol abuse were also cited as possible reasons for poor academic performance on the part of some first- year students. "At first-year level, there is a very thin line between the temptation to give in to the pressure of friends with distracting behavior and being assertive enough to remain focused on one's studies. A large number of first-years give in to peer pressure with the obvious result that they fail at the end of the year," said a student in one of the Entrepreneurial Studies focus groups.

From the focus group and individual interviews it was established that indeed there are institutional factors that contribute to students' low success rates, especially in the first year. This is in keeping with Tinto's model as adapted by Longden (2004). In addition, it corroborates the view that sometimes it is not the students who are under-prepared for higher education. Rather, it is the universities that are under-prepared for the task of embracing the diversity that is characteristic of the expansion in student populations with the advent of democracy in South Africa (Boughey, 2011). One of the institutional factors which impacts negatively on first-year pass rates is large class size as a result of which, in the words of one focus group interviewees, '....the average student becomes just a number with no individual contact or interaction with the lecturers.' The tutor system was said to be helping but some tutorial groups were still said to be too big for individual interaction between tutors and students. The quality of tutoring in some subjects was, however, also brought to question. The lecturers all concurred that it was not possible to individually interact with all their students because of the sheer size of some classes.

Poor career guidance, as mentioned by both the student and lecturer participants in many cases resulted in some students choosing programmes that they had neither the passion nor aptitude for. Often students choose programmes for no other reason than the increased chances of getting bursaries. This, coupled with the low bar set for admission to university was said to be a major contributory factor to high failure and drop-out rates among most first-years.

Other factors external to students which, in the view of both students and lecturers, failure at first year level could be attributed to included failure to find suitable accommodation and lack of financial support, especially for those students coming from disadvantaged backgrounds. Some of these students struggle with basics such as food, text books and stationery, and other learning gadgets such as calculators. This is in keeping with the view that low success rates at university level are often a result of failure to support living costs (Breier \& le Roux, 2012) and that "...performance is incontrovertibly correlated with indicators of socio-economic status" (Gilmour, Christie \& Soudien, 2012: 40). This was confirmed by one student participant who said, "It is not easy to focus fully on your studies when you are worrying about where you are going to get the next meal, rent or money for transport to go home."

\section{Conclusion and Recommendations}

The results of the study show that the general view of the students and lecturers is that while low success rates amongst first-year university students are largely attributable to under-preparedness on the part of the students, there is also an extent to which it can be attributed to factors which have nothing to do with under-preparedness. The dimensions of under-preparedness which were perceived to be contributory to low first-year success rates included weaknesses in students' literacy and numeracy skills; limitations in terms of ability to engage in critical thinking; exposure to only limited subject content in comparison to what the students have to handle at university level; dearth in infrastructure and equipment at the schools from which the students came resulting in some of the students coming into contact with certain forms of technology only at university and weaknesses in the quality of teaching received by the students. Factors other than under-preparedness which, in the view of most of the participants in the study also contributed to low first-year success rates could be put into two categories. In the first category could be placed pyscho-social factors, internal to the individual such as personal discipline, ability to adjust to the university experience and the socio-economic background from which the students came. The second category was made up of factors that are external to the student. These included institutional factors such as class size and the amount of support given to first-year students to ensure that they succeed in their studies.

The problems in the South African school system are well documented and acknowledged by stakeholders such as the government, teachers and the universities. Though the results are not immediately apparent, a lot is being done to 
improve the school system, - the construction of new schools in some rural areas and the School Intervention Programmes being just but two examples. In light of its findings, the study therefore recommends enhancement of these programmes. However, given that some students from good schools struggle with university studies, it is evident that a school background alone does not guarantee success at first year level. The study therefore further recommends greater collaboration between the schools and universities intended to identify the extent and nature of the school-university gap. This is an area of potential further research through which programmes can then be designed to assist with narrowing the gap between school and university. Since it is not practically possible for all high school leavers to be enrolled at university, there should also be programmes to narrow the gap between high school and other post-school pathways such as Further Education Colleges and trades training. An education system is only as good as its teachers. There is therefore a need for the South African government to continue investing in the initial and continuous training of teachers financially and in terms of human resources and infrastructure. It is perhaps time to revisit the decision to close down teachers' colleges.

The need for all stakeholders to appreciate the enormity, complexity and urgency of the challenge of increasing student success can hardly be over-emphasized as increasing students' access to university which does not translate to successful completion of programmes is an exercise in futility. Individual institutions cannot solve the problem on their own. Only through intra and inter-institutional collaboration is a meaningful difference likely to be realized (Grayson, 2013).

At many universities, the success of the University's First Year Experience initiatives notwithstanding, there is still a need to enhance institutional support for first-years in order to ameliorate the negative impact of psycho-social and institutional factors on first-year success rates. Initiatives aimed at enriching the learning experience would most likely inculcate a greater appreciation of learning by the first-years as well as go a long way in ensuring an improvement in both their success rates and retention till graduation. This is in light of the possibilities for success that adequate academic support provides even to the so-called under-prepared students. High failure rates, it needs to be appreciated, not only lead to high drop-out rates, but also defeat the government's intention to redress the imbalances of the past through increasing access to higher education. By extension, high failure and drop-out rates are a violation of the students' right to tertiary education and pose a serious threat to the country's future economic and social stability. Since the problem cannot be wished away, the time for practical action to address it is now.

\section{References}

Bernstein, A., McCarthy, J., \& Oliphant, R. (2013). Maths teaching in SA adds up. Mail \& Guardian 25 October.

Bloch, G. 2009. The Toxic Mix: What's wrong with South African Education and how to fix it. Cape Town, Tafelberg

Booyse, J.J., le Roux, C.S., Seroto, J., Wolhuter, C.C. 2012 A History of Schooling in South Africa: Method and Context, Van Schaik, Pretoria

Bradbury, J. \& Miller, R. 2011. A failure by another name: The phenomenon of under-preparedness. South African Journal of Science 107 (3) : (12-119)

Child, K. 2013. Teachers are clueless: State report shows educators' limitations are retarding pupils from the earliest grades. The Times, 6 May.

Chipangura, C. 2013. Maths failure robs SA of much-needed skills. The Star, 23 July.

Chipangura, C. 2013. Poor grasp of maths basics adds up to fewer scientists. The Star, 20 August

Crous, S. 2013. Education and development: What is your company doing?. Mail \& Guardian, 15 March

Davids N. 2013. Children doomed in schools of shame- Eastern Cape visit has delegation in shock. Sunday Times, 28 April.

Grayson, D. 2013. Guru on student success to visit SA. Mail \& Guardian, 16 August.

Gilmore, D., Christie, P. \& Soudien, C. 2012. Lofty education ideals narrow a system driven by test results.' Mail \& Guardian, 14 September.

Govender, P. 2013. New Focus on Maths teachers. Sunday Times, 27 October.

Hartshorne, K. 1999. The Making of Education Policy in South Africa, Oxford University Press, Cape Town

Jansen, L. 2013. Shocking literacy stats. The Star 17 October

John,V. 2012. Time to go back and hit the books. Mail \& Guardian, 2 November.

Joshua, A.A. \& Adelabu, M.A. 2012. Improving infrastructure for sustainable quality assurance practice in secondary schools in Ondo State, South West Nigeria. International Journal of Research Studies in Education, 1 (1): (61-68)

Krueger, R.A. 1994. Focus groups: A practical guide for applied research. Newbury Park, CA: Sage.

Longden, J. 2004. Retention and student success in Higher Education. Open University Press, London

Maher, C. 2011. Academic writing ability and performance of first-year university students in South Africa. Unpublished M. Ed thesis, University of the Witwatersrand.

Mayring, P. 2000. Qualitative Content Analysis in Forum. Qualitative Social Research 1(2): (43-56)

Mcfarlane, D. 2012. Blade's promises are educational: The minister's budget-vote speech traversed competing priorities. Mail \& 
Guardian, 4 May.

Morgan, D.L. 1988. Focus groups as qualitative research, London, Sage

Mthethwa, N. 2013. How could I have failed varsity: High- quality private schooling is no guarantee of success at varsity. Mail \& Guardian, 11 January.

Mtshali, N 2012. Ramphele slates 'deceptive' education system. The Star, 23 March.

Mtshali, N. 2013. Many schools still don't have all their textbooks. The Star, 3 April 3

Mtshali, N. 2013. Pupils lose in teacher strike. The Star, 25 April.

Mtshali, N. 2013. This English exam paper, she take the cake. The Star, 8 May.

Mtshali, N. 2013. Dinaledi maths, science programme 'falling.' The Star, 20 August.

Mtshali, N. 2013' Report paints bleak picture of higher education. The Star, 27 August.

Nkosi, B. 2012. Curriculum must bed down: For optimal results, teachers must become expertly familiar with what they have to teach.Mail \& Guardian, 18 May.

Nkosi, B. 2013. The textbook time bomb-schools across the country still have book shortages because of inadequate budgeting. Mail \& Guardian 23 August.

Noon, M. 2013. Forget results- teach children how to learn. Mail \& Guardian, 15 February.

Nyakudya, B. 2013.Feature on education. Afropolitan Magazine Issue 32

Patton, M.Q. 1987. How to Use Qualitative Methods in Evaluation. Newbury Park, CA: Sage,

Prew, M. 2013. Our maths mindset doesn't add. Mail \& Guardian, 5 July.

Prince, R. and Yeld, N. 2012. A bridge too far for school learners: New testing data reveal worryingly few matriculants are equipped for higher education. Mail and Guardian 12 October.

Rivera, C. 1984. Language Proficiency and academic achievement. Multilingual Matters Private Limited, London

Robson, C. 1995. Real World Research- a resource for social scientists and practitioner researchers. Oxford, Blakchood

Skiti, S. 2013. Dejected pupils know nothing will change. Sunday Times, 28 April.

Spaull, N. 2012. Back to the real basics: Education cannot progress if we do not pay more attention to elementary skills.Mail \& Guardian, 11 May.

Spaull, N. 2013. Absentee teachers are a thorn on our side: But the state should be focusing on the quality of teachers' work when they're in the classroom. Mail \& Guardian, 8 March

Tinto, V. 2002. Enhancing student persistence: connecting the dots, a paper presented at Optimizing the Nation's Investment: Persistence and Success in Post-secondary Education Conference, University of Wisconsin, Wisconsin

Van Schalkwyk, S. 2008. Acquiring Academic Literacy: A Case of First-Year Extended Degree Programmes at Stellenbosch University. Unpublished $\mathrm{PhD}$ thesis

Veriava, F. 2013. Angie's cop-out on school quality: Her new infrastructure norms limit the state's legal obligations to poor schools. Mail \& Guardian, 25 January.

Verrijdt, A. 2012. Apartheid psychology persists in schools.Mail \& Guardian, 27 January. (pp32)

\section{Internet sources}

http://www.universityworldnews.com (accessed 01 April 2013)

http://www.news24.com/South Africa (accessed 05 April 2013)

http://www.uj.ac.za/EN/News/Pages (accessed 17 April 2013) 